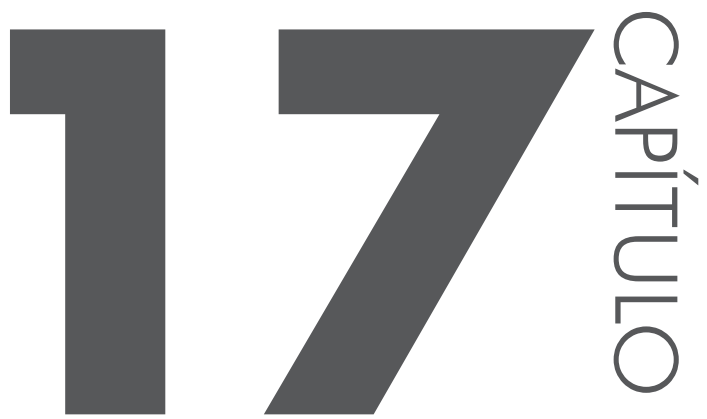

\title{
PROGRAMA E MÉTODO DE LEITURA NA REFORMA EDUCACIONAL GOIANA DE 1930
}

Juliana de Sousa Naves ${ }^{1}$ Ana Maria Gonçalves ${ }^{2}$

Resumo: O presente trabalho aborda a situação do Ensino Primário em Goiás, no que se refere à organização e às propostas para o ensino da leitura, assim como aos métodos indicados no currículo estabelecido pela reforma de 1930 . No Brasil, em Goiás não foi diferente, a última década do século XIX foi marcada pela

1 Unidade Acadêmica Especial de Educação, Universidade Federal de Goiás/Regional Catalão, Catalão/GO, Brasil

2 Unidade Acadêmica Especial de Educação, Universidade Federal de Goiás/Regional Catalão, Catalão/GO, Brasil

E-mail de contato: juliananaves30@hotmail.com 
centralidade dos debates em torno da educação e a defesa do Ensino Primário para todos, como elemento estratégico do projeto liberal de sociedade. Nesse contexto difundia-se a ideia de uma escola nova para a formação do homem novo, articulada com as exigências do desenvolvimento industrial e o processo de urbanização. Inspirados nas experiências educacionais europeias, os legisladores brasileiros passaram a reformar a instrução pública no país. A primeira lei goiana sobre o Ensino Primário foi a Lei $\mathrm{n}^{\circ} 13$, de 23 de julho de 1835 . No período subsequente, inúmeras outras foram implantadas. Analisar as orientações para o ensino de leitura no programa de ensino de 1930 é o objetivo desta pesquisa, tendo por princípio que o prescrito não é necessariamente o que se realiza em sala de aula. Os resultados indicam que o programa de ensino proposto para as escolas primárias goianas de 1930, no que refere à leitura e suas práticas, apresenta um conjunto de prescrições para os mestres, quanto aos conteúdos, métodos, materiais e seus usos, , todavia, reconhece os limites advindos da ausência de formação dos professores.

Palavras-chave: História do Ensino Primário; Ensino da leitura; Método e práticas de ensino de leitura.

Abstract: This study addresses the situation of primary education in Goiás, as regards the organization and proposals for the teaching of reading, as well as the methods set out in the curriculum established by the reform of 1930. In Brazil, in Goiás was no different to last decade of the nineteenth century was marked by the centrality of debates around education and the defense of universal primary education as a strategic element of liberal society project. In this context it is diffused the idea of a new school for the formation of the new man, articulated the demands of industrial development and urbanization process. Inspired by European educational experiences, Brazilian legislators began to reform public education in the country. The first goiana law on primary education was Law No. 13 of 23 July 1835. In the period, numerous others were deployed. Analyze the guidelines for teaching reading in 1930 teaching program is the goal of this research, with the principle that the prescribed is not necessarily what is done in the classroom. The results indicate that the educational program proposed for Goiás primary schools in 1930 in terms of reading and its practices, presents a set of prescriptions for the teachers, as to the contents, methods, materials and their uses, recognizing, however, the limits arising from the lack of training them.

Keywords: History of Primary Education; Reading instruction; Method and reading teaching practices.

\section{INTRODUC̣ÃO}

A primeira lei goiana sobre o Ensino Primário foi a Lei $n^{\circ} 13$, de 23 de julho de 1835. Nela se definiram várias regras para a organização das escolas de 
primeiras letras em Goiás, as quais estabeleciam, por exemplo, o que seria ensinado, onde o governo deveria criar escolas, a obrigação dos pais de colocarem os filhos na escola, o perfil do professor. Com essa lei esperava-se abrir caminhos para constituição de uma rede de escolas.

Assim, a partir do ano de 1835, várias escolas primárias foram criadas em diferentes localidades, desde as cidades até as aldeias indígenas. Vale lembrar que a criação de uma escola exigia número suficiente de crianças em idade escolar. Nesse sentido, a lei estabelecia que a escola atendesse, no mínimo, a dezesseis alunos, e que se a frequência não fosse cumprida, ela poderia ser fechada. Se a escola não estivesse de acordo com a legislação ou estivesse sem professor, também poderia ser suprimida. Desse modo, em alguns momentos, escolas foram fechadas com a justificativa da diminuição de gastos da província, como fica claro na fala do presidente da província de Goiás: "No intuito de diminuir a despeza que tanto cresceo nestes últimos tempos, com a luxuosa creação de escolas inúteis, indico-vos a conveniência de supprimir algumas passando a servir nas que forem conservadas os professores vitalícios que por ventura tiverem exercício naquellas" (Relatório do presidente da província de Goiás, Luiz Augusto Crespo, 1878, p. 10 apud ABREU, 2006, p. 35).

Percebe-se, nesse trecho, o tratamento menor conferido pelo presidente da província à educação. Fica claro que ele considerava a criação de escolas um fator inútil e um luxo caro para ser mantido pelo poder público. No entanto, era dever dos presidentes das províncias estender a instrução primária gratuita a todo cidadão brasileiro, tanto do sexo masculino quanto do sexo feminino. Lembrando que o número de escolas femininas era bem menor, segundo Abreu (2006),

[...] as escolas masculinas disseminaram-se por todo o território goiano, já as femininas foram abertas nas localidades econômica e politicamente mais importantes da província. Comparando com as masculinas, seu número era muito menor; esse fato pode ser justificado, provavelmente, pela forma patriarcal de organização da sociedade brasileira e goiana, na qual a educação feminina se limitava às "prendas domésticas”, que deveriam ser aprendidas e ensinadas no seio familiar (ABREU, 2006, p. 30).

Um aspecto a ser ressaltado, segundo a autora, é que o governo encontrava dificuldades de prover escolas em algumas regiões, as quais sofriam ataques de índios, e nas aldeias, pois os professores, com salários baixos, não queriam arriscar contato com pessoas consideradas "não civilizadas".

Os regulamentos de instrução, resoluções e atos, com o passar das décadas, sofreram diferentes modificações, feitas de acordo com as necessidades e pontos de vista distintos, com o objetivo de unificar a organização e a estruturação das escolas. Um exemplo é que, nas primeiras décadas do século XIX, as escolas 
eram divididas em femininas e masculinas, mas, no decorrer dos anos, visto que algumas escolas não tinham número suficiente de alunos, passou a constar, nos regulamentos, que as escolas femininas poderiam se tornar escolas mistas.

A finalidade do ensino ministrado nas escolas de primeiras letras, por um tempo considerável, era a educação literária, moral e religiosa da classe pobre. Posterior a 1862, passou-se ao desenvolvimento das faculdades intelectuais e morais das crianças (Regulamento de Instrução de 1884; 1887). Nas escolas dos aldeamentos, dava-se ênfase, também, à civilização, à catequese e, vale destacar, à profissionalização para a formação de mão de obra para o trabalho, ensinando o ofício de ferreiro para os homens e o filatório para as mulheres (ABREU, 2006).

Cabe ressaltar que inúmeras leis foram criadas, relatórios oficiais apresentados entre os anos finais do século XIX e ao longo da Primeira República, em que se advogava a necessidade de renovação educacional, com a introdução de métodos modernos, qualificação dos professores, programas de ensino enciclopédicos, arquitetura, mobiliário e materiais próprios. Dentre as reformas educacionais realizadas no estado de Goiás, definimos por trabalhar com a Reforma do Ensino Primário do ano de 1930. Essa reforma teve um caráter emblemático, pois resultou de um convênio entre o governo goiano e o paulista, que propiciou a vinda de uma "missão pedagógica" ao estado para reformular o ensino. Assim, auxiliado por técnicos paulistas, o Secretário José Gumercindo Marques Otero organizou um novo regulamento para a instrução primária, o qual se transformou no Decreto n ${ }^{\circ} 10.640$, de 13 de fevereiro de 1930.

Junto com esse Regulamento, foi proposto um novo Programa de Ensino para as escolas primárias. Buscando compreender o sentido dessa reforma, indagamos o que o programa propunha quanto ao ensino da leitura nas escolas primárias goianas. Nessa perspectiva, buscamos refletir sobre os conteúdos, métodos e práticas prescritos para as escolas primárias nos anos de 1930.

\section{REGULAMENTO DO ENSINO PRIMÁRIO DE 1930}

De acordo com o prescrito no Regulamento do Ensino Primário do Estado de Goiás, decreto ${ }^{\circ}$ 10.640, de 13 de fevereiro de 1930, art. $2^{\circ}$, o Ensino Primário era ministrado às crianças, de 7 a 12 anos, podendo variar sua duração de acordo com algumas especificidades: $1^{\circ}$ nas escolas isoladas rurais, eram oferecidos dois anos de curso; $2^{\circ}$ nas escolas isoladas urbanas, três anos de curso; $3^{\circ}$ nos grupos escolares, três anos de curso; $4^{\circ}$ nas escolas complementares, três anos de curso, aos maiores de 10 anos, portadores de diplomas de escolas estaduais primárias ou de título de habilitação em exame de suficiência.

Fica claro o tratamento de inferioridade conferido às escolas rurais, com menos tempo de curso e com provimento de vagas diferenciado, ao se indicar 
que quando não houvesse nenhum normalista, o governo contrataria professor não diplomado, enquanto nos grupos escolares, a exigência era da contratação de professores normalistas e com experiência, conforme o artigo:

Art. 90 - Quando não houver nenhum normalista que se candidate ao provimento das escolas vagas, em requerimento, o governo as proverá de professor não diplomado, tendo preferência os que apresentarem diploma de escola superior e os que exhibirem documentos comprobatorios da conclusão do curso de algum dos grupos escolares do Estado, ou por pessoa idônea, mediante attestado da autoridade escolar do districto onde estiver localizada a escola (ESTADO DE GOYAZ, 1930, p. 23).

A partir da leitura do Regulamento, é possível inferir que alguns princípios básicos eram indispensáveis à nova educação que se propugnava, dentre eles, destacam-se: a finalidade do Ensino Primário não se resumia apenas à instrução, mas, sobretudo, à educação que contribuísse para o desenvolvimento mental e moral; a instrução era coletiva, porém, o professor deveria se preocupar com a especificidade de cada criança; a escola deveria ser um espaço de socialização, preparando as crianças para viver em sociedade; o professor deveria ensinar as matérias de forma atraente, visando à compreensão e não à memorização, formando um aluno crítico e reflexivo, capaz de usar as noções aprendidas no seu cotidiano.

Para que esses princípios fossem seguidos, o Regulamento estabelece a necessidade de colaboração de várias pessoas e órgãos competentes, desde professores, diretores, inspetores, conselho superior até o Presidente do Estado. Por exemplo, algumas competências importantes do conselho superior de ensino, prescritas no art. 36, eram: estudar e propor ao governo as medidas destinadas ao aperfeiçoamento do ensino normal e primário; estudar e ensaiar a introdução gradativa dos recentes processos de instrução primária de Decroly, Dalton, Montessori, Plane, sugerindo meios práticos de adotá-los na instrução pública do estado; organizar os programas do Ensino Primário, dentre outras.

As competências dos inspetores estão previstas no art. 43, dentre elas: dar instrução aos professores, para melhor desenvolvimento dos programas; inspecionar pessoalmente as classes, quando o julgarem necessário ou for requerida a sua presença, devendo logo em seguida proceder à crítica da aula a que assistirem, sugerindo modificações aos métodos, processos e orientação do ensino, para torná-lo mais eficiente.

No art. 65, consta a obrigatoriedade de todas as crianças de 7 a 12 anos frequentarem escola. Porém, logo abaixo, um fato chama a atenção: para uma criança ser matriculada, precisaria de um atestado médico que provasse que ela não tinha defeitos físicos repugnantes, que não convivia com pessoas atacadas de moléstia contagiosa e não sofria dessas moléstias. Aparece, também, que quando a criança não tivesse meios indispensáveis ao vestuário, higiene e decência, ela ficaria isenta 
da obrigatoriedade de frequentar a escola. Se compararmos com os dias de hoje, percebemos a diferença quanto à inclusão de todas as crianças nas escolas.

Um fato interessante é que o Regulamento de 1930, em vários artigos, traz referência quanto ao número máximo de alunos por classe, o que não acontecia nos regulamentos do século XIX, nos quais ficava claro apenas o número mínimo de alunos para o funcionamento das escolas. Esse fato se vincula possivelmente às modernas concepções de ensino que se advogava.

Referente às matérias escolares, a grade para o Ensino Primário do Regulamento de 1930 prescrevia:

$1^{\circ}$ ANNO - leitura, calligraphia, linguagem (linguagem oral e lingua escripta), arithmetica, formas, desenho, geographia, historia, instrucção moral e civica, lições de cousas, música, trabalhos manuaes, gymnastica; $2^{\circ}$ ANNO - leitura, calligraphia, linguagem (linguagem oral e lingua escripta), arithmetica, formas, desenho, geographia, historia, instrucção moral e civica, lições de cousas, música, trabalhos manuaes, gymnastica; $3^{\circ}$ ANNO - leitura, calligraphia, linguagem (linguagem oral e linguagem escripta), arithmetica, geometria, desenho, geographia, historia, instrucção moral e civica, sciencias physicas e naturaes, música, trabalhos manuaes, gymnastica. E a Escola Complementar era composta das seguintes matérias - Língua vernácula e Calliphasia, Francez, Mathematica e Lógica, Geographia e Historia do Brasil, Sciencias Physicas e Naturaes, Música, Desenho, Trabalhos manuaes e Gymnastica.

No que se refere ao ensino de leitura, o Regulamento traz dois artigos que consideramos importante destacar, para compreendermos melhor a importância que lhe era dado:

Art. 217 - Os livros da biblioteca ficarão à disposição dos alunos que os queiram ler, em horas designadas pelo diretor, que, em casos excepcionais, poderá permitir que sejam retirados, mediante recibo e pelo prazo máximo de oito dias.

$[\ldots .$.

Art. 249 - São deveres dos professores:

11. observar o dia de leitura, às quintas feiras reunindo-se na biblioteca do grupo ou na sala que for designada, dedicando, no mínimo, duas horas a leituras, particularmente relativas a método de ensino, outras matérias indispensáveis à cultura magisterial;

O que dizer desses dois artigos? O tempo destinado à leitura seria suficiente? Podemos perceber que se incentivava a leitura, porém com restrições, data e hora marcadas, como se a leitura não estivesse presente em todas as matérias.

O Regulamento traz, ainda, no Título IX, Das instituições escolares, Capítulo II, mais elementos relacionados ao incentivo à leitura: o clube de leitura. São sete artigos que definem as seguintes regras: 
Art. 351 - Em cada grupo escolar serão organisados um ou mais clubes de leitura entre os alumnos das classes do segundo e terceiro annos.

Art. 352 - O clube terá por fim estimular a leitura de bons livros e favorecer o desenvolvimento do gosto na escola das obras; promover a leitura em voz alta e a audição intelligente por parte do auditório infantil, que assistir à leitura; desenvolver as aptidões de expressão por exposições oraes, que farão os alumnos do resultado de suas leituras e da sua opinião sobre os assumptos sujeitos à deliberação do clube; augmentar a bibliotheca escolar pelo próprio esforço dos membros do clube, os quaes deverão conservar e encadernar os livros da bibliotheca.

Art. 353 - A direcção do clube pertencerá aos próprios alumnos, que deverão eleger três dentre elles para constituírem a administração.

Art. 354 - Os professores devem, por todos os meios ao seu alcance, estimular e favorecer o bom funccionamento do clube, sem comtudo, interferir na sua administração e no jogo espontâneo das actividades infantis. A sua acção se limitará a encorajar, por meio de conselhos, as crianças mais atrazadas a fazerem exercícios repetidos de leitura, de maneira a poderem pertencer ao clube; a suggerir opportunidades para a organização de allocuções a serem pronunciadas; a criar situações favoráveis à reunião do clube e freqüente realização de leituras, em voz alta.

Art. 355 - O clube organizará, depois de apresentadas as sugestões e propostas por parte de seus membros, uma lista de cinco livros, que, a seu julgamento, devem ser lidos pelos alumnos de cada classe, antes de terminado o anno lectivo.

Art. 356 - Depois de lidos pelos alumnos pertencentes ao clube os cinco livros, designarão, em sessão ou sessões especiaes, dentre elles o que, a seu juízo, deve ser recommendado como o mais próprio para ser adoptado como livro do quarto anno.

Art. 357 - Os livros assim escolhidos pelo clube serão submettidos ao exame dos professores e demais technicos do ensino primário e propostos às consideração do conselho superior do ensino.

Percebe-se, por meio desses artigos, a tentativa de incentivar a leitura, porém fica a dúvida se o que estava prescrito realmente acontecia na prática das salas de aulas. Nesse sentido, apresentamos a seguir uma breve discussão sobre o currículo.

\section{PENSANDO O CURRÍCULO}

Analisar o processo do ensino de leitura na reforma educacional goiana de 1930, demanda compreender: o que é o currículo, como surgiu e o que fundamenta sua construção. Nesse sentido, percorremos a História do Currículo, trazendo ideias de pesquisadores sobre o conceito de currículo.

Conforme Goodson (1995), o interesse pela história do currículo remonta à primeira fase da chamada Nova Sociologia da Educação, iniciada na Inglaterra por Michael Young e outros. Assim, como reafirma Muniz (2014): 
Vale lembrar que essa abordagem nasce com os estudos da Nova Sociologia da Educação, considerada a primeira corrente sociológica que privilegiou a discussão e problematização do currículo enquanto construção social. Para a perspectiva sócio-histórica, o currículo e as disciplinas escolares não são algo dado, natural, neutro e inocente, mas um produto social e histórico, que envolve relações de interesse e poder, conflitos, e demandas externas e internas, que determinam o conhecimento que deve ser sistematizado e ensinado nas escolas (MUNIZ, 2014, p. 21).

De acordo com Goodson (1995), currículo é a forma como organizamos o conhecimento e o saber, visando à sua transmissão. Ele não é fixo, está sempre sujeito a modificações, em busca de aperfeiçoamento, ou seja, o currículo não é "algo pronto de uma vez por todas; é, antes, algo a ser definido, onde, com o tempo, as mistificações tendem a se construir e reconstruir sempre de novo" (GOODSON, 1995, p. 78).

Para complementar o conceito do termo currículo, o historiador canadense do currículo, George Tonkins o define como: "[...] o curso aparente ou oficial de estudos, caracteristicamente constituído em nossa era por uma série de documentos que cobrem variados assuntos e diversos níveis, junto com a formulação de tudo - "metas e objetivos", conjuntos e roteiros - que, por assim dizer, constitui as normas, regulamentos e princípios que orientam o que deve ser lecionado" (TONKINS apud GOODSON, 1995, p. 117).

Nesse sentido, a construção do currículo está ligada ao contexto social, cultural e histórico, por isso é importante lembrar que ele sofre transformações durante sua história, pois assim entenderemos não só o currículo no passado, mas sim sua construção até os dias atuais. Se sua constituição é um processo social, vale destacar os conflitos sociais entre as diferentes tradições e concepções, as rupturas e as ambiguidades que se fizeram, para chegar a conhecimentos socialmente válidos a serem transmitidos às gerações futuras, assim como afirma Goodson:

O processo de fabricação do currículo não é um processo lógico, mas um processo social, no qual convivem lado a lado com fatores lógicos, epistemológicos, intelectuais, determinantes sociais menos "nobres" e menos "formais", tais como interesses, rituais, conflitos simbólicos e culturais, necessidades de legitimação e de controle, propósitos de dominação dirigidos por fatores ligados à classe, à raça, ao gênero (GOODSON, 1995, p. 8).

Nesse sentido, Goodson, chama a atenção para a importância de analisar a história de currículos fracassados, esquecidos e com menos prestígio, os quais são tão importantes quanto os bem-sucedidos, pois o currículo é resultado de uma construção histórica.

Para Goodson (1995), o currículo tem ligação direta com a formação de pessoas, inclusive produz identidades e subjetividades sociais determinadas, por isso a 
história do currículo deve se preocupar com os determinantes sociais e políticos do conhecimento educacionalmente organizado. A pesquisa de Goodson considera, portanto, “[...] que as categorias pelas quais vemos e construímos hoje o currículo educacional são resultado de um lento processo de fabricação social, no qual estiveram presentes conflitos, rupturas e ambiguidades" (GOODSON, 1995, p. 11).

O conceito de currículo é "multifacetado, construído, negociado e renegociado em vários níveis e campos" (GOODSON, 1995, p. 67). Goodson (1995) defende que, ao estudar o currículo, devemos entendê-lo "primeiramente em nível da própria prescrição, mas depois também em nível de processo e prática” (GOODSON, 1995, p. 67). Ele define "currículo prescrito" como sendo o currículo escrito, pré-ativo, tal como é elaborado pela comunidade intelectual e política; e "currículo em ação", como aquele correspondente ao currículo em atividade, em interação, principalmente, realizado na sala de aula (GOODSON, 1995 apud MUNIZ, 2014, p. 28).

Diante dessas duas vertentes do currículo, o prescrito e o em ação, podemos fazer relação com o Programa de Ensino de 1930, pois o documento prescrevia recomendações aos mestres, porém reconhecia que nem todos seriam capazes de realizá-las, assim como afirma Goodson: “O que está prescrito não é necessariamente o que é apreendido, e o que se planeja não é necessariamente o que acontece" (GOODSON, 1995, p. 78).

Diante disso, fica clara a importância do professor, enquanto socializador do currículo, o qual tem autonomia nas decisões referentes ao currículo e ao ensino. Portanto, segundo Goodson, se faz necessário "uma teoria sobre como atuam, reagem e interagem as pessoas envolvidas na contínua produção e reprodução de currículo" (GOODSON, 1995, p. 64). Em síntese, é importante uma abordagem para a construção do currículo que não pense somente na teoria, mas, também na prática, pois elas são indissociáveis.

Enfim, de acordo com Muniz (2014, p. 25), o currículo é a prescrição e a prática, e um elemento fundamental para a compreensão da cultura escolar. Assim, é importante reafirmar com a autora que:

[...] a partir dessas definições, compreendo o currículo como uma ferramenta de seleção da cultura, de organização do conhecimento, em contexto histórico determinado, condicionado por fatores socioculturais, econômicos, políticos e institucionais, internos e externos à escola. No processo de seleção e organização da cultura, o currículo produz sua própria cultura, que é institucionalizada e se manifesta por meio da legislação, das políticas curriculares, dos programas de ensino, das grades, diretrizes e referenciais curriculares, dos livros didáticos, entre outros. O currículo, portanto, constitui-se em um conhecimento propriamente escolar, num curso de estudos a ser seguido, que requer uma aprovação social e que ganha vida no espaço prático e real da sala de aula (MUNIZ, 2014, p. 26). 
Concluindo, o currículo é de extrema importância na organização escolar, pois propõe mudanças, inovações sobre o que, como e por que ensinar, ajudando o professor na formação de seus alunos. Sendo assim, é importante investigá-lo e conhecer seus mecanismos de produção e reprodução, uma vez que o currículo é "uma palavra-chave com expressivo potencial de exumação, exame e análise da parte dos estudiosos” (GOODSON, 1995, p. 105 apud MUNIZ, 2014, p. 29).

\section{O PROGRAMA DO ENSINO DE LEITURA: REFLETINDO SOBRE AS CONCEPÇÕES, MÉTODOS E PRÁTICAS PROPOSTAS}

O Programa de Ensino de 1930, ou seja, o currículo para as escolas primárias foi criado para orientar os professores sobre o que e como ensinar. No que se refere às aulas de leitura traz indicação de conteúdos, métodos e práticas a serem usados por eles. Analisaremos a seguir as orientações relativas ao ensino de leitura no $1^{\circ}$, no $2^{\circ}$ e no $3^{\circ}$ ano do Ensino Primário.

Para o $1^{\circ}$ ano do Ensino Primário, a primeira orientação sobre leitura refere-se à indicação do uso do método analítico ${ }^{3}$, porém é feita uma observação indicando que esse método deve ser usado apenas por professores que soubessem ensiná-lo de modo conveniente, aos demais era recomendado que utilizassem o método que tivessem maior domínio, desde que as primeiras aulas fossem coletivas.

Nota-se o despreparo que se fazia presente nas escolas. O programa já foi escrito sabendo que encontraria barreiras para ser disseminado. A falta de formação dos professores aparentemente não preocupava, visto que se indicava apenas que encontrassem outra forma de ensinar, em vez de tentar promover cursos de aperfeiçoamento dos professores, para uma melhor qualidade do ensino. Assim, ao mesmo tempo que o programa se inspirava na renovação pedagógica, propondo outras dinâmicas, há o reconhecimento do uso, na escola, de práticas educativas que denotam o ensino tradicional.

A partir da leitura do Programa de Ensino, podemos inferir que o método proposto era uma tentativa de mudar a forma do ensino de leitura. Propunha-se ensinar a leitura como um todo, ensinar primeiramente sentenças e palavras (concreto), para depois ensinar sílabas e letras (abstrato). Porém, podemos indagar

3 “[...] os métodos analíticos orientam a apropriação do código escrito pelo caminho do todo para as partes (de palavras, sentenças ou textos para a decomposição das sílabas em grafemas/ fonemas). Apesar de procurarem situar a relação grafema/fonema em unidades de sentido, como palavras, sentenças e textos, os métodos analíticos tendem a se valer de frases e textos artificialmente curtos e repetitivos, para favorecer a estratégia de memorização, considerada fundamental” (BRASIL, 2008, p.12). 
se isso aconteceu ou não, diante do fato do próprio programa permitir que se o professor não soubesse usar o método analítico, que usasse qualquer outro.

As orientações eram divididas em dez partes, sendo elas:

$\left.1^{\circ}\right)$ Fase preparatória;

$2^{\circ}$ ) Revisão das sentenças;

$\left.3^{\circ}\right)$ Análise das sentenças;

$4^{\circ}$ ) Leitura de tipo de forma;

$\left.5^{\circ}\right)$ Entrega da Cartilha;

$\left.6^{\circ}\right)$ Reconhecimento das sílabas;

$\left.7^{\circ}\right)$ Aprendizagem das letras;

$8^{\circ}$ ) Leitura de palavras derivadas, de polissílabos etc;

$9^{\circ}$ ) Leitura do primeiro livro;

$10^{\circ}$ ) Recapitulação do primeiro livro.

No primeiro momento, a proposta era a apresentação oral dos objetos e gravuras, para conduzir as crianças a formularem sentenças completas. Essa atividade serviria para ajudar o professor a dividir a turma em A, B e C, de acordo com a idade e o desenvolvimento intelectual de cada criança, ou seja, havia os melhores e os piores, e a própria escola se encarregava de fazer essa separação, promovendo assim a exclusão, a segregação. No entanto, o programa colocava essa divisão como estímulo aos alunos mais fracos. Será que isso serviria de estímulo ou de retraimento?

Logo após essa divisão, os alunos de cada uma das turmas eram chamados ao quadro e o professor fazia perguntas sobre "cousas" ou gravuras relacionadas aos assuntos das primeiras lições da cartilha adotada. O foco da atividade deviria estar voltado para conduzir as crianças a formularem sentenças e não apenas a letra em si. As sentenças seriam escritas no quadro, lidas pelo professor e depois repetidas pelos alunos. O programa deixa claro que esse exercício de memorização não consistia na leitura no verdadeiro sentido do termo, porém as sentenças serviriam de caminho para chegar às palavras, e isso já seria um avanço diante do ensino que era adotado anteriormente, focado em letras isoladas.

No segundo momento, após o estudo de algumas séries de lições, propunha-se a recapitulação das sentenças, a leitura mental, e, ainda, exigia-se do aluno uma leitura natural, que demonstrasse que ele tinha aprendido o sentido do que lera. A pedagogia "moderna" do programa orientava o ensino da leitura e escrita simultaneamente. Então, as sentenças eram copiadas também no caderno de caligrafia, mesmo que no começo fossem cópias indecifráveis, pois acreditava-se 
que gradativamente elas ficariam mais legíveis e perfeitas. Podemos perceber que a despeito da dita modernização, a memorização e a cópia estavam ali impregnando o ensino.

Posteriormente, seria feita a análise das sentenças. Elas seriam fragmentadas para se ensinasse às crianças o frasear, ajudando-as na correção da leitura. As palavras das sentenças dominadas pelos alunos eram colocadas em colunas, e com elas seriam formadas novas sentenças, que os alunos leriam "por um relancear synthetico dos olhos".

Até esse momento, as lições da cartilha tinham sido dadas no quadro negro, mas já era hora de preparar as crianças para a leitura no próprio material. Ainda no quadro, seriam ensinadas as sentenças em letra de impressão e em manuscrito vertical, assim como nas cartilhas. No quinto momento, quando se acreditava que as crianças já sabiam ler, era entregue a cartilha. Desse momento em diante, as lições seriam dadas no quadro e depois lidas no livro, acreditando que ministrado de duas formas diferentes, o ensino seria variado e interessante, teria bom êxito e seria evitado decorar.

Para a parte do reconhecimento das sílabas, o programa orienta que fossem feitas listas de palavras, que se iniciassem com a mesma sílaba, chamando a atenção da criança para esse elemento da palavra, a qual até então ela considerou como um todo. Para que aprendessem a distinguir as sílabas, seria feita a análise oral de uma série de palavras, e logo após as palavras seriam escritas no quadro, com as sílabas separadas. As sílabas decompostas serviriam para a formação de novas palavras, que formariam novas sentenças, as quais seriam lidas e teriam o significado explicado pelos alunos. No programa, estava prescrito que era indispensável o conhecimento sintético da sílaba, desde que a criança só chegasse à sílaba isolada pela análise da palavra. Esse conhecimento era considerado importante, pois na língua portuguesa a pronúncia não se divorcia muito da forma gráfica.

A aprendizagem das letras era feita por meio de listas de palavras que começassem com a mesma letra e com exercícios de rimas. A letra inicial da palavra era o foco, porém, era importante ensinar toda a palavra, para que a criança chegasse ao final da cartilha conhecendo todo o alfabeto.

Realizava-se, ainda, a leitura de palavras derivadas, de polissílabos, mostrando para o aluno as dificuldades fonéticas do português, exercitando palavras formadas pelos sufixos mais comuns, que indicam flexões de gênero, número e grau.

Após todo esse processo de ensino da cartilha, podia-se considerar a criança apta para a leitura de um primeiro livro. Terminada a leitura, era feita a recapitulação.

Para o $2^{\circ}$ ano do Ensino Primário, o Programa de Ensino de 1930 trazia a seguinte orientação: ensino visando à leitura corrente, feita sem hesitação, com progressão de modo fácil e claro. Para que os alunos conseguissem ler dessa forma, 
era preciso que o professor ensinasse a boa articulação e a correta pronúncia das palavras, e que cuidasse das pausas e ligações. O objetivo era a leitura feita naturalmente, como se fosse uma conversa informal.

Cada nova lição de leitura era trabalhada em, no mínimo, três aulas consecutivas, e era dividida em três partes:

$\left.1^{\circ}\right)$ Preparo da leitura: narração objetiva da história escolhida feita pelo professor; leitura de toda a lição feita pelo professor, acompanhada de leitura silenciosa dos alunos; identificação, no quadro, de palavra difíceis e de novas expressões, acompanhadas de seu significado; divisão da leitura com os alunos, interpretando cada trecho lido; leitura corrente do professor, que indicava o estudo da lição em casa.

$2^{\circ}$ ) Tomar a lição: reprodução da lição por dois ou três alunos; leitura e interpretação de pequenos trechos; uso das palavras explicadas em sentenças orais; leitura de toda a lição por um aluno.

$3^{\circ}$ ) Leitura corrente pelo maior número de alunos possíveis.

Esse processo, segundo as orientações do programa, era lento, porém eficiente. Vale lembrar que no caso de erro na leitura, o aluno teria que repetir corretamente o período, descobrindo e corrigindo sua falta, por seu próprio esforço. Diante das observações sobre as orientações para o ensino de leitura, fica a dúvida se esse método realmente era eficiente e se ele era, de fato, posto em prática.

$\mathrm{Na}$ classe do $3^{\circ}$ ano, se esperava uma boa leitura corrente. No programa se recomendava que o professor insistisse para que o aluno lesse de maneira correta, respeitando a pontuação, pronunciando de forma clara e natural. O programa deixa uma "indireta" para os professores, nos seguintes termos: "Mas a boa leitura só se aprende pela imitação e o melhor modelo é a leitura do mestre, que precisa tornar-se um bom leitor." Então, antes de tudo, quem precisava se tornar um bom leitor eram os mestres, e, diante do fato de nem todos terem formação adequada, fica a questão se os professores liam da forma almejada pelo programa.

A leitura deveria ser feita em voz alta e precedida, sempre, da leitura mental de toda a lição, pois essa leitura em silêncio era a mais utilizada na vida. A leitura de forma dialogada deveria ser realizada sempre que possível, e nesses momentos cada aluno se tornaria um personagem da história, dando a entonação apropriada.

No $3^{\circ}$ ano, deveria ser feita a leitura complementar de revistas, jornais, livros, de acordo com o adiantamento dos alunos, tratando de "lições de cousas" ${ }^{4}$, de assuntos históricos, geográficos, para auxiliar na aquisição de conhecimentos.

4 Maiores informações confiram Bastos (2013) e Valdemarin (1998; 2004). 
O programa, para essa classe, orientava, também, a leitura declamada de prosa ou verso, leitura expressiva de gêneros literários diversos, interpretação de exposição do assunto lido, uso dos sinais de pontuação, manejo do dicionário de português.

Enfim, o Programa de Ensino de 1930, no que se refere ao ensino de leitura e suas práticas, prescrevia passo a passo, série após série, recomendações explícitas aos mestres, ainda que se reconhecesse que nem todos seriam capazes de realizá-las.

\section{CONSIDERAC̣ÕES FINAIS}

O presente trabalho nos ajudou a compreender o sentido da reforma de $1930 \mathrm{e}$ o que se propunha para a renovação do Ensino Primário. Os programas e métodos para o ensino de leitura eram inovadores, porém incompatíveis com a realidade, ou seja, com a precária formação dos professores, que, inclusive, é insinuada como o motivo de não se conseguir colocar em prática o que estava prescrito.

Se as reformas educacionais têm como objetivo a melhoria da educação, seria importante que se pensasse em mudanças que pudessem acontecer de fato, não somente ficassem no papel, na prescrição, e, principalmente, que houvesse disposição em derrubar as barreiras que surgissem durante o processo. No caso da reforma de 1930, percebemos que havia a necessidade de formar os professores para que eles conseguissem cumprir os objetivos da proposta, mas cabe interrogar se o peso não estaria todo numa única dimensão, se não temos aí uma centralização que descura de análises de conjunto da realidade da escola goiana à época.

A despeito de não podermos afirmar o quanto do proposto se realizou, reconhecemos o esforço dos legisladores goianos em orientar a instrução no estado nos moldes do que ocorria nos estados mais desenvolvidos, incluindo aí a solicitação do apoio técnico, no caso a missão pedagógica.

Com relação aos método e às atividades propostas, percebemos a influência da Pedagogia Nova na preocupação com os interesses da criança, nas fases de desenvolvimento, no princípio ativo e até na indicação de referências teóricas vinculadas a essa nova vertente educativa.

\section{REFERÊNCIAS}

ABREU, S. E. A. de. A instrução primária na província de Goiás no século XIX. 2006. Dissertação. (Doutorado em Educação: História, Política, Sociedade) - Pontifícia Universidade Católica de São Paulo, São Paulo, 2006.

BASTOS, M. H. C. Método intuitivo e lições de coisas por Ferdinand Buisson. Hist. Educ., Santa Maria, v. 17, n. 39, pp. 231-253, 2013. Disponível em: <http://www.scielo. br/pdf/heduc/v17n39/a13v17n39.pdf>. Acesso em: 5 jun. 2015. 
BRASIL. Pró-Letramento: Programa de Formação Continuada de Professores dos Anos/ Séries Iniciais do Ensino Fundamental: alfabetização e linguagem. - ed. rev. e ampl. incluindo SAEB/Prova Brasil matriz de referência/ Secretaria de Educação Básica Brasília, DF: Ministério da Educação, Secretaria de Educação Básica, 2008. 364 p. BRETAS, G. F. História da instrução pública em Goiás. Goiânia: CEGRAF/UFG, 1991. CAMPOS, F. I. Coronelismo em Estado periférico. Goiânia: Ed. da UFG, 1983. CHAUL, N. F. Caminhos de Goiás: da construção da decadência aos limites da modernidade. Goiânia: Ed. da UFG/ Ed. da UCG, 1997.

CARVALHO, M. M.C. de. A escola e a República. São Paulo: Brasiliense, 1989.

ESTADO DE GOYAZ. Programma de Ensino para as Escolas Primárias. 1930. Estado de Goyaz. Decreto no 10.640, de 13 de fevereiro de 1930. Regulamento do Ensino Primário do Estado de Goyaz.

GOODSON, I. Currículo: teoria e história. Petrópolis: Vozes, 1995.

MOACYR, P. A instrução e as províncias: subsídios para a história da educação no Brasil - 1834-1889. São Paulo: Companhia Editora Nacional, 1940. 3 v.

MUNIZ, T. A. A disciplina Ensino Religioso no currículo escolar brasileiro: institucionalização e permanência. 2014. 208 f. Dissertação. (Mestrado em Educação) Universidade Federal de Goiás, Catalão/GO, 2014.

SOUZA, R. F. de. Tempos de infância, tempos de escola: a ordenação do tempo escolar no ensino público paulista 1892-1933. Educação e Pesquisa, São Paulo, v. 25, n. 2, jul/ dez, 1999.

Inovação educacional no século XIX: a construção do currículo da escola primária no Brasil. Cadernos Cedes. Ano XX, n. 51, nov. 2000.

VALDEMARIN, V. T. Método intuitivo: os sentidos como janelas e portas que se abrem para o mundo interpretado. In: SOUZA, R. F.; VALDEMARIN, V. T.; ALMEIDA, J. S. O legado educacional do século XIX. Araraquara: Ed. da UNESP, p. 63-105, 1998.

. Estudando as lições de coisas: análise dos fundamentos filosóficos do Método de Ensino Intuitivo. Campinas: Autores Associados, 2004. 
